\title{
MATHEMATICAL MODELS FOR NONLINEAR SOIL BEHAVIOR
}

Berevoescu Ileana Carmen, Senior Lecturer Eng. PhD, Spiru Haret University, Faculty of Architecture, email: carmenberevoescu62@gmail.com, cberevoescu@ yahoo.com,

\section{Rezumat}

Solicitarea seismica are, in realitate, un caracter ciclic neregulat. Aceasta se poate echivala cu un numar determinat de solicitari ciclice uniforme, echivalente din punct de vedere al efectului. Modelarea comportamentului solului la solicitari ciclice se realizează de obicei prin stabilirea unei relații pentru încărcarea primară, de tipul $\tau=\mathrm{f}(\gamma)$ şi trasand apoi "curba efort-deformatie", în care $\tau$ este efortul și $\gamma$ este deformatia de forfecare. Pentru modelarea comportarii neliniare al terenului, se folosesc modele neliniare. Cele mai cunoscute sunt modelul hiperbolic si modelul Ramberg-Osgood.

Cuvinte cheie: infrastructura, rigiditate, amortizare, deformatie, model hiperbolic, model Ramberg-Osgood

\section{Abstract}

Actually, the seismic movement has an irregular cyclic character.This can be equivalent to a determined number of uniform cyclical stresses equivalent in terms of effect.

Modeling the behavior of the soil to cyclical stress, is usually done, by establishing a relationship for primary loading like $\tau=f(\gamma)$ and after drawing the diagram "effortless strain curve", in which $\tau$ is the stress, and $\gamma$ is shear deformation. For modeling nonlinear behavior of the soil, we used like nonlinear models. The best known are the hyperbolic model and the Ramberg-Osgood model.

Keywords: infrastructure, stiffness, damping, strain, hyperbolic model, RambergOsgood model

\section{GENERAL CONSIDERATIONS}

Dynamic requests that act on an infrastructure are in the form of a vibrational movement. The answer depends on your request infrastructure directly as signal propagation mode, magnitude and distance to propagation. The propagation of 
the movement is a problem extensively studied over time. Stiffness parameters are defined and amortization of soil use in infrastructure design. The soil is considerate like a extensible halfspace, homogene, isotropically and infinite. For modeling nonlinear behavior of the soil [5], we used nonlinear models, like :

- the hyperbolic model

- the Ramberg-Osgood model.

\section{MATHEMATICAL MODELS OF COMPUTATION FOR NONLINEAR BEHAVIOR OF SOIL}

Actually, the seismic movement has an irregular cyclic character, can be equivalent to a determined number of uniform cyclical stresses equivalent in terms of effect.

Modeling the behavior of the soil to cyclical stress, is usually done, by establishing a relationship for primary loading like $\tau=\mathrm{f}(\gamma)$ and after drawing the diagram "effortless strain curve", in which $\tau$ is the stress, and $\gamma$ is shear deformation.

For modeling nonlinear behavior of the soil [5], we used nonlinear models like:

- The Hyperbolic Model

- The Ramberg-Osgood Model.

\subsection{The Hyperbolic Model}

Stress-strain relationship that defines "curve model" of this model is the hyperbolic equation proposed by Kondner and Zelenko in 1963,[5],:

$$
\tau=\frac{G_{\mathrm{o}} \gamma}{1+\frac{G_{\mathrm{o}}}{\tau_{f}} \gamma}
$$

where:

- $\mathrm{G}_{\mathrm{o}}$ is the initial shear modulus (maximum deformation module);

$-\tau_{f}$ is the shear resistance of the soil . 
For the domain of very small deformations, the primary transverse deformation module (or shear modulus) $\left(\mathrm{G}_{\mathrm{o}}\right)$, can be considered to be equal to elastic shear modulus.

In 1972, Hardin and Drnevich [4], defined the reference deformation $\gamma_{\mathrm{r}}$.

$$
\gamma_{r}=\frac{\tau_{f}}{G_{0}}
$$

Introducing the relationship that expresses the reference deformation into the hyperbolic equation, the expression of the shearing shear modulus is obtained at a certain point $\mathrm{A}\left(\gamma_{\mathrm{a}}, \tau_{\mathrm{a}}\right)$ :

$$
\frac{G}{\sigma_{0}}=\frac{1}{1+\frac{\gamma_{a}}{\gamma_{r}}}
$$

In terms of damping ratio (D) is reached next relationship:

$$
D=\frac{4}{\pi}\left(1+\frac{1}{\frac{\gamma_{a}}{\gamma_{r}}}\right) \cdot\left[1-\frac{1}{\frac{\gamma_{a}}{\gamma_{r}}} \ln \left(1+\frac{\gamma_{a}}{\gamma_{r}}\right)\right]-\frac{2}{\pi}
$$

The damping ratio (D) can also be expressed by:

$$
D=\frac{4}{\pi} \frac{1}{1-\frac{G}{G_{0}}}\left[1-\frac{\frac{G}{G_{0}}}{1-\frac{G}{G_{0}}} \ln \left(\frac{1}{\frac{G}{G_{0}}}\right)\right]-\frac{2}{\pi}
$$

In the hyperbolic model, there are only two independent parameters, the initial shear modulus $(\mathrm{Go})$ and the shear resistance $\left(\tau_{\mathrm{f}}\right)$; This has in some cases 
difficulty in that it is difficult to express both dependent strain shear modulus, damping ratio as well as only these two parameters.

The main inconvenience is that once the reference deformation (strain) has been determined, $\left(\gamma_{\mathrm{r}}\right)$, the relation that binds to a shear modulus value damping ratio, which also depends on the deformation (strain), flow automatically and there is no adjustment possible parameters to get a good agreement with experimental data on damping.

To overcome this difficulty, in 1972, Hardin and Drnevich [4] proposed the using of the next relationship:

$$
D=D_{\mathrm{o}}\left(1-\frac{G}{G_{0}}\right)
$$

where (Do) represents the damping ratio at high deformations when the shear modulus $(\mathrm{G})$ becomes very small relative to the initial value.

They propose to enter a new parameter (Do), which allows better match of the model with experimental data.

The most convenient is to determine model parameters based on physical constants of some significance as may be determined by testing.

In this regard, the initial shear modulus at very low deformations (Go) and shear strength $\left(\tau_{\mathrm{f}}\right)$ are the most consistent constants to be included as model parameters [3].

The amount of shear strength at break, is generally determined in the laboratory by direct shear testing or triaxial test.

It is preferable that the resistance parameters to be determined in cyclical conditions.

In some cases, Hardin and Drnevich suggested the use of the MohrCoulomb failure criterion to determine shear resistance. $[4,6]$

The value of the initial shear modulus in the very low deformation range is determined by laboratory tests with the resonance column or in situ, by wave propagation tests.

\subsection{The Ramberg-Osgood Model}

Stress-strain relationship that defines " model curve " of this model is: 


$$
\frac{\gamma_{a}}{\gamma_{r}}=\frac{\tau}{\tau_{y}}\left[1+\alpha\left|\frac{\tau}{\tau_{y}}\right|^{r-1}\right]
$$

Where:

- $\left(\gamma_{\mathrm{y}}\right)$ and $\left(\tau_{\mathrm{y}}\right)$ are the deformation and the shearing effort;

- $\alpha$ and $r$ are constants which can adjust the shape and position of the curve.

Values $\left(\gamma_{\mathrm{y}}\right)$ and $\left(\tau_{\mathrm{y}}\right)$ must be chosen so as to have a physical significance.

In 1975 , Richart proposed that the parameters $\left(\gamma_{y}\right)$ and $\left(\tau_{y}\right)$ to be defined by the following relationships:

$$
\begin{aligned}
& \tau_{y}=C_{1} \tau_{f} \\
& \gamma_{y}=C_{1} \tau_{f} / G_{0}=C_{1} \gamma_{r}
\end{aligned}
$$

where $\mathrm{C} 1$ is a constant less than unity.

In this case, $\left(\tau_{\mathrm{y}}\right)$ represents a fraction of the shear resistance, and the shear deformation $\left(\gamma_{\mathrm{y}}\right)$ is the same fraction of the reference deformation $\left(\gamma_{\mathrm{r}}\right)$.

Considering the relations proposed by Richard [7] for $\left(\tau_{\mathrm{y}}\right)$ and $\left(\gamma_{\mathrm{y}}\right)$, we obtain equation "effort-deformation curve " like as:

$$
\tau=\frac{G_{0} \gamma}{1+\alpha\left|\frac{\tau}{C_{1} \tau_{f}}\right|^{r-1}}
$$

In 1980, Hara [5] proposed to use the shear strength for $\left(\tau_{y}\right)$ and the reference strain for $\left(\gamma_{\mathrm{y}}\right)$,

$$
\begin{aligned}
& \tau_{y}=\tau_{f} \\
& \gamma_{y}=\gamma_{r}=\tau_{f} / G_{0}
\end{aligned}
$$


Then, the equation of "effort - deformation curve " will have the next form:

$$
\tau=\frac{G_{0} \gamma}{1+\left|\frac{\tau}{\tau_{f}}\right|^{r-1}}
$$

It should be noted that the relation stress-strain as proposed by Hara (eq. 11) is substantially the same as the one proposed by Richart (eq.9), because the inclusion of the parameter $\mathrm{C} 1$, does not cause any structural change in relation to the stress-strain represented by Ramberg-Osgood. $[5,6]$

From the above relation (Hara), we obtain the expression of $\mathrm{G}$ module:

$$
\frac{G}{G_{0}}=\frac{1}{1+\alpha\left|\frac{G \gamma_{a}}{G_{0} \gamma_{r}}\right|^{r-1}}
$$

To calculate the damping ratio, it reaches the next relationship:

$$
D=\frac{2}{\pi}\left(\frac{r-1}{r+1}\right) \cdot\left(1-\frac{G}{G_{0}}\right)
$$

In contrast to the hyperbolic model which contains only two independent parameters, the Ramberg-Osgood model contains four parameters for the expression of stress-strain relationship and therefore have greater opportunities for riding with experimental data.

In the case of the Ramberg-Osgood model, the initial shear modulus (Go) and shear strength $\left(\tau_{\mathrm{f}}\right)$ can be determined by the same method as in the case of the hyperbolic model. Once apprised of the values of these two constants of the earth, the reference deflection $\left(\gamma_{\mathrm{r}}\right)$ can be determined using its definition above. The other two remaining parameters, $\alpha$ and $\mathrm{r}$ may be determined as follows:

\section{- The " $\alpha "$ parameter}

In 1980, Hara used the deformation at break $\left(\gamma_{\mathrm{f}}\right)$ to determine the $\alpha$ parameter [5]. 
In Hara "model curve " equation are inserted: $\tau=\tau_{\mathrm{f}}$, for $\gamma=\gamma_{\mathrm{f}}$ and is obtained the next relationship

$$
\alpha=\frac{G_{0}}{G}-1
$$

Because

$$
G_{f}=\frac{\tau}{\gamma_{f}}
$$

The advantage of this way of $\alpha$ parameter determination consists in that the properties may be represented with accuracy in particular, in the field of large deformations, and can be avoided in this way disadvantage RambergOsgood model to lead to unrealistic large efforts in the field of large deformations [6].

\section{- The " $r$ parameter}

It is preferable to determine the parameter " $r$ ", from the knowledge of the damping characteristics of the soil. Because in the Ramberg-Osgood model, the damping ratio is related to the ratio of the modules (G / Go), the value of "r" can be determined if, for a given load level, are known values (D) and (G / Go). When it is known damping ratio at break $\left(D_{f}\right)$, the value of "r" results from the relationship:

$$
r=\frac{1+\frac{\pi D_{f}}{2} \frac{1}{1-\frac{G_{f}}{G_{0}}}}{1-\frac{\pi D_{f}}{2} \frac{1}{1-\frac{G_{f}}{G_{0}}}}
$$




\section{CONCLUSIONS}

In seismic analysis of soil-structure interaction, the modeling of soil foundation with consideration of nonlinear and hysteretic nature, it is an issue of great importance. For modeling nonlinear behavior of the soil, we used like nonlinear models. The best known are the hyperbolic model and the RambergOsgood model.

In the hyperbolic model, there are only two independent parameters, the initial shear modulus (Go) and the shear resistance $\left(\tau_{f}\right)$; This has in some cases difficulty in that it is difficult to express both dependent strain shear modulus, damping ratio as well as only these two parameters.

The Ramberg-Osgood model contains four parameters for the expression of stress-strain relationship and therefore have greater opportunities for riding with experimental data.

In the case of the Ramberg-Osgood model, the initial shear modulus (Go) and shear strength $\left(\tau_{\mathrm{f}}\right)$ can be determined by the same method as in the case of the hyperbolic model.

\section{REFERENCES}

[1]. C. BEREVOESCU: "Efecte ale interactiunii seismice teren-structura la constructii ingropate si partial ingropate", Teza de doctorat, UTCB, 2000;

[2]. C. BEREVOESCU, M. STEFANICA:"Modele matematice de calcul pentru comportarea neliniara a pamantului exprimata prin curba efort-deformatie",UTCB, Conferinta Nationala de Cai Ferate, 25.10. 2017;

[3]. ANDREI. S.:"Cercetari privind stabilirea parametrilor dinamicipe baza analogiei dintre pamanturi", ICB,1993;

[4]. HARDIN, B.O., DRNEVICH, V.P.:"'Shear Modulus and Dumping in Soils: Measurement \& Parameter Effects", SMFD, ASCE, 98/1972;

[5]. ICH Bucuresti: "Studiul influentei terenului asupra solutiei de fundare in cazul terenurilor coezive ( CNE tip CANDU)", Contract nr. 807/1987;

[6]. INCERC Bucuresti: "Normativ pentru proiectarea fundatiilor", Contract nr. 40/1995;

[7]. RICHART, F.E. Jr.:"Some Effects of Dynamic Soil-Structure Interaction", Proceeding of ASCE, vol. 101, 1975. 